\title{
Fingertip skin models for analysis of the haptic perception of textiles
}

\author{
Izabela Luiza Ciesielska-Wrobel $^{1,2}$, Lieva Van Langenhove ${ }^{2}$, Katarzyna Grabowska ${ }^{3}$ \\ ${ }^{1}$ Department of Textiles, Ghent University, Zwijnaarde, Belgium \\ ${ }^{2}$ Department of Chemistry, Textiles and Innovative Processes, Hautes Études d’Ingénieur, Lille, France \\ ${ }^{3}$ Institute of Architecture of Textiles, Lodz University of Technology, Lodz, Poland \\ Email: Izabela.CiesielskaWrobel@UGent.be
}

Received 27 October 2013; revised 28 November 2013; accepted 15 December 2013

Copyright (C) 2014 Izabela Luiza Ciesielska-Wrobel et al. This is an open access article distributed under the Creative Commons Attribution License, which permits unrestricted use, distribution, and reproduction in any medium, provided the original work is properly cited. In accordance of the Creative Commons Attribution License all Copyrights (C) 2014 are reserved for SCIRP and the owner of the intellectual property Izabela Luiza Ciesielska-Wrobel et al. All Copyright (c) 2014 are guarded by law and by SCIRP as a guardian.

\section{ABSTRACT}

This paper presents finite element models of the fingertip skin which have been created to simulate the contact of textile objects with the skin to gain a better understanding of the perception of textiles through the skin, the so-called hand of textiles. Many objective and subjective techniques have already been developed for analysing the hand of textiles; however, none of them provide exact overall information concerning the sensation of textiles through the skin. As the human skin is a complex heterogeneous hyperelastic body composed of many particles, some simplifications had to be made at the early stage of building the models; however, their utilitarian value was maintained. The models relate only to mechanical loading of the skin. They predict a low deformation of the fingertip skin under the pressure of virtual heterogeneous material: acrylic, coarse wool, and steel.

\section{KEYWORDS}

Fingertip Skin; Sensation of Textiles through the Skin; Skin Model; Finite Element Model; Abaqus CEA

6.10-2.

\section{INTRODUCTION}

\subsection{The Hand of Textiles}

The hand of textiles is a crucial element influencing the purchase of textiles by individuals and therefore it has been intensively analysed since the beginning of the twentieth century. The hand (or handle) has so far been defined as:

1) A subjective assessment of a textile obtained by the sense of touch;

2) A property judged as a function of the feel of material: its roughness, smoothness, harshness, pliability, thickness, and so on;

3) A quality expressed by an individual reaction through the sense of touch upon examining a fabric or one or more fabrics of the same quality [1] as presented on Figure 1.

On the basis of our own experience and studies we propose our own definition of the subjective hand of textiles:

"The hand of textiles based on the holding of the textile in a fist or gently between the fingers or the smoothing of the textile with the palm is an act of experiencing the textile's thickness and surface, the degree of softness and flexibility, and other textile physical features against the skin of the palm which evokes the impressions related with physical features of the material perceived by the palm skin sensors and transferred neurologically from the palm and finger skin receptors to the cerebral

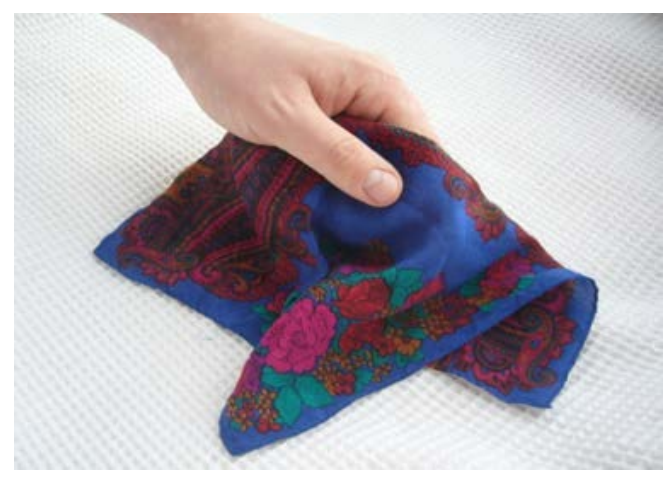

Figure 1. The estimation of the hand of woven silk fabric. 
cortex through the spinal cord. The judgement is given after referring to the personal experience of the person who makes this judgement as well as his or her natural skin sensibility.” [2].

According to the authors of this paper, the only way to better understand an ideal human haptic system is through the creation of an artificial system that works like this natural sense system. In the case of the hand of textiles, this organ is the skin of the hand of each person in which the perception system exists. At the same time, we propose an alternative solution to the existing, nonideal objective and subjective systems of hand measurements. The idea of these early stage studies is to create models of the fingertip skin section to detect mechanical deformation caused by textiles that are in contact with them.

\subsection{Contact with the Skin}

There are four types of skin senses:

1) Touch-grip (grip is a sustained touch),

2) Cold,

3) Warmth,

4) Pain [3-5].

When the skin comes into contact with an object, for example textile material, some of those sense organs react to that action. In the case of coarse wool knit fabric, which is often used for heavy winter sweaters which irritate the skin of the body, the senses involved would be touch sense, warmth sense, and possibly pain sense due to the rough surface of the woollen material and itchy effect caused by single fibres of wool.

The appropriate receptors that innervate the skin are activated by different stimuli, among other things by mechanical forces. The mechanical loading deforms the skin from a relaxed state, affecting mechanoreceptors in the skin [6,7]. In other words, when humans manipulate objects, the brain uses tactile afferent information related to the time course, magnitude, direction, and spatial distribution of contact forces, the shapes of contacted surfaces, and the friction between contacted surfaces and the digits.

\section{MATERIALS AND METHODS}

\subsection{Rationale and Methodology}

Skin has already been modelled many times and different approaches have been applied depending on the orientation of the studies. Simulating the wrinkling and ageing of the skin uses three constitutive models of each of the skin layers: the isotropic neo-Hookean strain energy function was applied to model the epidermis; the dermis was modelled by using an orthotropic-viscoelastic model; and the hypodermis was modelled using the quasi-linear approach [8-11]. In the case of predicting slowly adapt- ing mechanoreceptors' spike times, a two-dimensional (2-D) finite element model representing a microstructure of three layers of the skin was presented. Layers were modelled with a linear elastic material model [12]. In the case of studies related with the penetration of drugs through the skin [13], a viscoelastic skin modelling approach was used. Skin experiences some deformations when contacted with physical objects such as textiles, and therefore skin mechanics transform deflections from the skin's surface into distributions of stress. As a reaction to that stress, a strain spreads through the skin layers. A finite element method was used to model the skin mechanics. Three-dimensional (3-D) cross-sections of the fingertip skin were developed and analysed; however fingerprint lines, bones, nails, and mechanoreceptors were not included in the model. Models were constructed as isotropic elastic material. An elastic linear approach can be applied in that case due to low deformation of the skin (approx. $0.5-1.5 \mathrm{~mm}$ ) caused by the contact with textiles.

In the case of current studies four 3-D models were created in the program Abaqus CEA 6.10-2 Student Edition to determine the influence of three kinds of textiles on the stress-strain characteristic of those models and whether the models can detect any difference between those materials and steel knit structure. To simulate a deformation of the skin, two of the models were deformed by uniformly distributed pressure on the surface of the skin model, and in the case of two other models, fragments of virtual textiles in the form of cylinders were applied on the surface. The stress-strain analyses by the models were compared and findings were referred to the findings from studies related to subjective assessment of pieces of textiles by volunteers [14]. The reference findings concern studies of three materials knitted with leftright stitch. The first one was made of $100 \%$ acrylic yarn, the second of $100 \%$ coarse wool yarn, and the third of $100 \%$ stainless steel (the application of personal protection textiles against electromagnetic radiation). The idea was to compare knit fabrics having different physical features and consequently different hands. Twenty healthy volunteers ( 9 men, aged 21 - 54 years, mean $46 \pm$ 11 years, and 11 women, aged 21 - 57 years, mean $35 \pm$ 12 years) eligible for the study participated in making haptic judgements of the materials. All were informed about the purpose of the study and manner of touching the textiles. Then they shared their comments about the $100 \%$ acrylic set of cloths. All mentioned that they "liked" the fabric as it is soft and not rough. All mentioned that they "didn't like" the woollen sample of knit fabric as it is very rough and may easily cause the skin to itch. To conclude, the $100 \%$ acrylic piece of material had better haptic features; that is, the hand was better. The final part of the experiment involved a group of four healthy volunteers ( 1 man, aged 33 years, and 3 women, 
aged 33 - 45 years, mean $39 \pm 6$ years) who were eligible for the study. All were in-formed about the purpose of the study and manner of touching the textiles. They reported their opinions on the acrylic and woollen material (the same ones that were evaluated by the first group of volunteers). They all described the structure as fine, relatively elastic, but extremely rough — much rougher and heavier than a woollen knit structure and far stiffer than an acrylic one.

\subsection{Finite Element Models}

The first model (1) is a basic cube shape solid modelled as a linear elastic body with a Young's modulus of 80 $\mathrm{kPa}$ [12] and Poisson coefficient of 0.48 [12] (Figure 2). In that case no virtual textile simulated the contact with and deformation of the model, but it was a uniform pressure which deformed the skin. The values of the uniform pressure applied on the skin surface in the model were calculated on the basis of the mass surface density of textiles and referred to the appropriate textile material. The mass surface density of $100 \%$ acrylic knit fabric was $210 \mathrm{~g} / \mathrm{m}^{2}$, which corresponds to $0.00092 \mathrm{~N}$ working on the skin model surface of $0.9 \mathrm{~cm}^{2}$ (as the size of the model was $10 \mathrm{~mm}$ in length $\times 9 \mathrm{~mm}$ in width $\times 6 \mathrm{~mm}$ in height). The mass surface density of $100 \%$ coarse wool knit fabric was $226 \mathrm{~g} / \mathrm{m}^{2}$, which corresponds to 0.00099 $\mathrm{N}$ working on the skin model surface of $0.9 \mathrm{~cm}^{2}$. The mass surface density of $100 \%$ stainless steel knit structure was $286 \mathrm{~g} / \mathrm{m}^{2}$, which corresponds to $0.00126 \mathrm{~N}$ working on the skin model surface of $0.9 \mathrm{~cm}^{2}$. Generalized plane strain elements have been used for finger tip skin section modelling. The entire mesh of the fingertip skin section consists of 540 elements and 770 nodes. The mesh utilized eight-node, hexahedral, linear, reduced integration, hourglass control (C3D8R). The stress-strain analysis is presented in Table 1.

The second model (2) is a three-layered skin section model consisting of epidermis, dermis, and hypodermis with a Poisson coefficient of 0.48 for all the layers and Young's modulus of $136 \mathrm{kPa}$ for the epidemis; $80 \mathrm{kPa}$ for the dermis, and $34 \mathrm{kPa}$ for the hypodermis [12] (Figure 3). The values of the uniform pressure working on the surface of the epidermis were applied in the same manner as in the case of model (1).

The mesh utilized eight-node, hexahedral, linear, reduced integration, hourglass control (C3D8R). The entire mesh of the fingertip skin section consists of 90 elements for the epidermis, 286 for the dermis, and 84 for the hypodermis, with 220 nodes in the epidermis, 504 nodes in the dermis, and 168 nodes in the hypodermis. The layers were connected with each other using tie constraints. The stress-strain analysis is presented in Table 1.

The third model (3) is similar to the first model; however instead of applying a uniform pressure on the surface of the skin, five cylinders imitating the textiles were in contact with the skin surface (Figure 4).

Boundary conditions are imposed on the top and bottom surface (as in both previous models (1) and (2)) of the skin as well as on the textiles that are in contact with
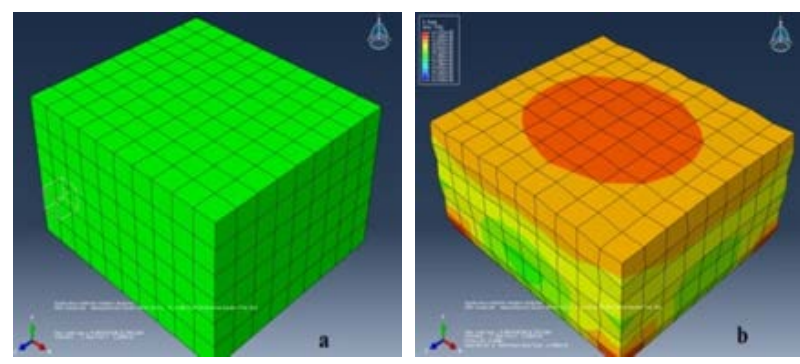

Figure 2. Geometry of the finite element models presenting fingertip skin sections: (a) a coarse meshed model without loading, (b) a coarse meshed model with a uniform distribution of $0.00092 \mathrm{~N}$ (corresponding to acrylic knit structure) placed on the top of the section in the form of pressure.

Table 1. The results of stress-strain analysis for model (1) and model (2) under the influence of uniform pressure corresponding to acrylic knit fabric, woollen knit fabric and steel knit structure.

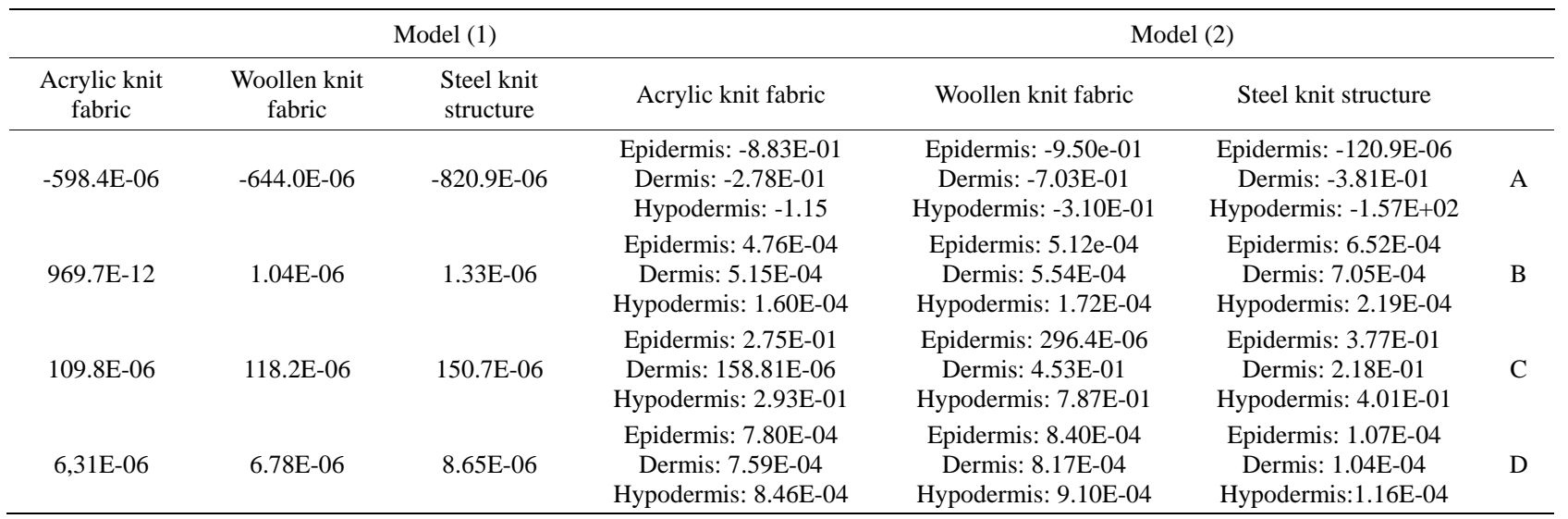

A: Min Stress S [Pa]; B: Min Strain E [\%]; C: Max Stress S [Pa]; D: Max Strain E [\%]. 
the top skin surface. Textiles that are in contact with the skin model surface are specified as a series of rigid cylinders with a friction coefficient of 0.3 (wool), 0.26 (acrylic), and steel (0.7) between them and skin surface. The stress-strain analysis is presented in Table 2.

The fourth model (4) (Figure 5) is similar to the second model; however instead of applying a uniform pressure on the surface of the skin, five cylinders simulating the textiles were in contact with the skin surface. The stress-strain analysis is presented in Table 2.

\section{RESULTS}

The stress-strain analysis for the model (1) shows that along with the increase in the mass surface density of the textile samples and consequently the force working on the fingertip skin section, the maximal stress and strain present a linear characteristic: for the piece of virtual textile with the lowest mass surface density the value of stress working on the surface of the virtual skin and the strain reaction are also the smallest.

The strain analysis in the model (2) seems to present a linear and a regular characteristic for all three skin layers. The highest value of strain was achieved for the dermiswhich is the second layer. The reason for that could be a different mesh type used for each skin layer. The coarsest mesh was applied for hypodermis as it represents the deepest layer of the skin and it is believed it should not react on the low deformation stimuli as vividly as epidermis and dermis.

In case of model (3) the stress causes a relative large deformation

The model (4) presents the deepest deformation for dermis. There are two aspects that could influence that. The first is mesh typed, which was the finer. The second is stiffness of the materials on the level $80 \mathrm{kPa}$, less than for epidermis. The strain reaction of all the models and all the skin layers is in accordance with mass perception of fabrics estimated by volunteers.

\section{DISCUSSION}

The aim of the study was to develop a tool which can be used as an alternative to existing subjective and objective methods of hand estimation.

Four 3-D models of the fingertip skin section were

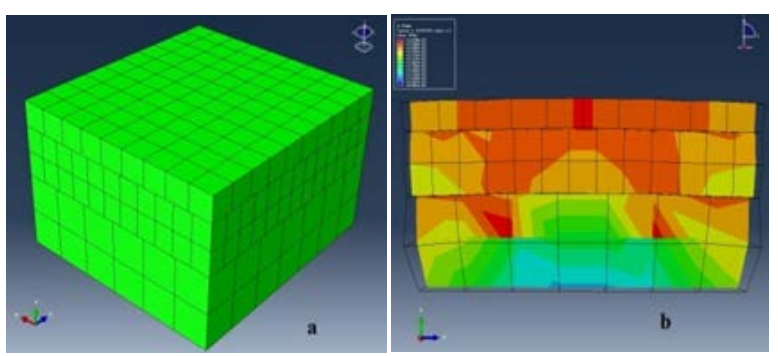

Figure 3. Geometry of the finite element models presenting fingertip skin sections: (a) a coarse three-layer model of the fingertip skin section meshed without loading, (b) a coarse meshed three-layer model with a uniform distribution of loading of $0.00126 \mathrm{~N}$ (corresponding to steel knit structure) placed on the top of the section in a form of pressure.
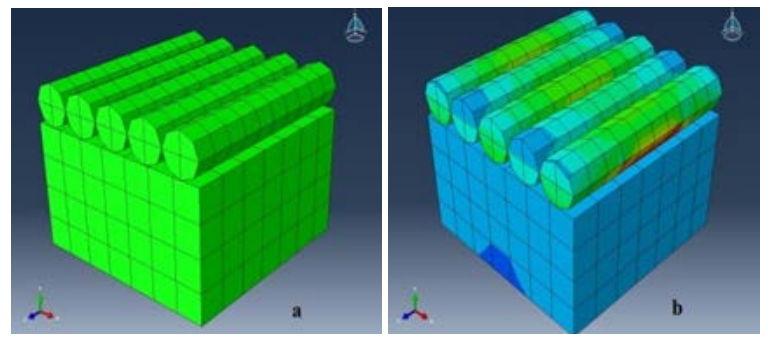

Figure 4. Geometry of the finite element models presenting fingertip skin sections together with cylinders imitating the woollen material: (a) a coarse meshed model without loading, (b) a coarse meshed model with rigid meshed cylinders.

Table 2. The results of stress-strain analysis for model (3) and model (4) under the influence of virtual structures corresponding to acrylic knit fabric, woollen knit fabric and steel knit structure.

\begin{tabular}{|c|c|c|c|c|c|c|}
\hline & Model (3) & & & Model (4) & & \\
\hline $\begin{array}{l}\text { Acrylic knit } \\
\text { fabric }\end{array}$ & $\begin{array}{l}\text { Woollen knit } \\
\text { fabric }\end{array}$ & $\begin{array}{l}\text { Steel knit } \\
\text { structure }\end{array}$ & Acrylic knit fabric & Woollen knit fabric & Steel knit structure & \\
\hline$-337.78 \mathrm{E}-06$ & $-363.5 \mathrm{E}-06$ & $-365.4 \mathrm{E}-06$ & $\begin{array}{l}\text { Epidermis: -809.126E-06 } \\
\text { Dermis: -492.202E-06 } \\
\text { Hypodermis: -1.17E-03 }\end{array}$ & $\begin{array}{l}\text { Epidermis: }-8.71 \mathrm{E}-01 \\
\text { Dermis: }-5.30 \mathrm{E}-01 \\
\text { Hypodermis: }-1.26 \mathrm{E}+02\end{array}$ & $\begin{array}{l}\text { Epidermis: }-1.1 \mathrm{E}-03 \\
\text { Dermis: -675.26E-06 } \\
\text { Hypodermis: }-1.6 \mathrm{E}-03\end{array}$ & A \\
\hline $24.45 \mathrm{E}-15$ & 29.5E-06 & 23.03E-06 & $\begin{array}{c}\text { Epidermis: } 1.40 \mathrm{E}-05 \\
\text { Dermis: } 3.19 \mathrm{E}-04 \\
\text { Hypodermis: } 1.77 \mathrm{E}-04\end{array}$ & $\begin{array}{c}\text { Epidermis: } 1.50 \mathrm{E}-04 \\
\text { Dermis: } 3.40 \mathrm{E}-04 \\
\text { Hypodermis: } 1.90 \mathrm{E}-04\end{array}$ & $\begin{array}{l}\text { Epidermis: } 1.9 \mathrm{E}-04 \\
\text { Dermis: 4.4E-04 } \\
\text { Hypodermis: } 2.4 \mathrm{E}-04\end{array}$ & B \\
\hline $24.4 \mathrm{E}-15$ & 23.3E-15 & 404.7E-18 & $\begin{array}{l}\text { Epidermis: -241.1E-06 } \\
\text { Dermis: 314E-06 } \\
\text { Hypodermis: 304.7E-06 }\end{array}$ & $\begin{array}{l}\text { Epidermis: -2.6E-01 } \\
\text { Dermis: 3.4E-01 } \\
\text { Hypodermis: 3.3E-01 }\end{array}$ & $\begin{array}{c}\text { Epidermis: -330.6E-06 } \\
\text { Dermis: 430E-06 } \\
\text { Hypodermis: 417.35E-06 }\end{array}$ & $\mathrm{C}$ \\
\hline 109.6E-15 & 104.5E-15 & $1.9 \mathrm{E}-15$ & $\begin{array}{c}\text { Epidermis: 5.31E-04 } \\
\text { Dermis: } 7.32 \mathrm{E}-04 \\
\text { Hypodermis: } 7.52 \mathrm{E}-04\end{array}$ & $\begin{array}{l}\text { Epidermis: 5.7E-04 } \\
\text { Dermis: 7.8E-04 } \\
\text { Hypodermis: 8.1E-04 }\end{array}$ & $\begin{array}{c}\text { Epidermis: 7.27E-04 } \\
\text { Dermis: } 1 \mathrm{E}-04 \\
\text { Hypodermis: } 1.03 \mathrm{E}-04\end{array}$ & $\mathrm{D}$ \\
\hline
\end{tabular}

A: Min Stress S [Pa]; B: Min Strain E [\%]; C: Max Stress S [Pa]; D: Max Strain E [\%]. 


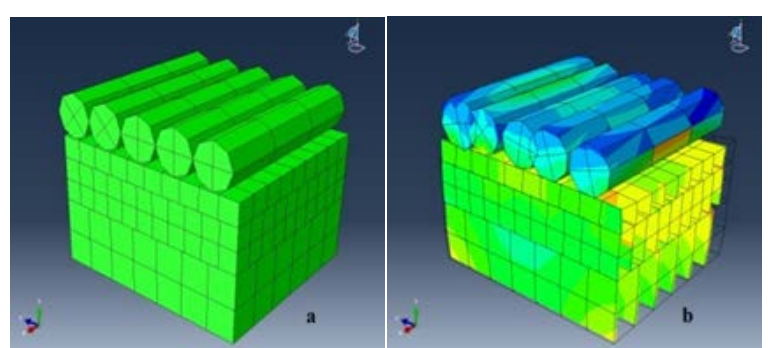

Figure 5. Geometry of the finite element models presenting fingertip skin sections together with cylinders simulating the steel knit structure: (a) a coarse meshed model without loading, (b) a coarse meshed model with rigid meshed cylinders.

created as a first step toward gaining a better understanding of the perception of textiles through the skin. The models created, (1), (2), (3), and (4), show similar ability to detect deformation. The deformation aimed to simulate the reaction/sensation of textiles in reality.

To verify the results of the simulation, the results of subjective estimation performed by volunteers were used. According to them the acrylic knit fabric was the softest and according to the laboratory studies its mass surface density was the lowest. The woollen knit fabric was much rougher; however it was more delicate in touch compared with a steel knit structure, whose mass surface density was the highest.

When considering only the mass surface density it seems to be logical that when the mass surface density or pressure applied on the surface is higher, the potential stress and strain are also higher for the linear stressstrain characteristic of the material being exposed to the pressure.

Of course the models presented in this study are simplifications of real skin however still some conclusions can be drawn.

The variations of models (2) and (4) in reference to stress analysis are lower than in case of models (1) and (3), which suggests that sharing the skin model into three layers could be meaningful.

Stress characteristic in case of models (1) and (2) is chaotic; however it is believed that the reason for that could be the applied mesh type.

The higher precision in building the model of the skin, e.g. more skin layers with different material properties, finding the proper mesh type, the more realistic results. It is believed future developments of the model should include the use of a more anatomically accurate skin surface, models should contain papillae lines that may influence detection of the mass surface density by the lower layers of the skin. The separate issue is the matter of temperature detection by the skin model surface which may have a great impact of the estimation of the virtual textiles. In the real process of estimation of textiles the thermal properties of textiles are crucial as it has a great contribution in estimation of final hand of textiles.

\section{CONCLUSIONS}

The models presented in this study have been demonstrated to be capable of replicating the changes that occur in the behaviour under the influence of uniform pressure on the surface of the skin and pressure related with the simulated textiles.

Further developments of the models like thermal and load coupling are highly required.

Other types of textiles with differentiated mass surface density should be introduced in the study to clearly verify the role of the mass surface density of textiles which stay in contact with the skin surface.

\section{ACKNOWLEDGEMENTS}

We would like to acknowledge funding provided by: 1) European Commission for Marie Curie Intra European Fellowship for Career Development-Project Acronym CREATION, no 253594 and 2) Polish National Science Centre for "Basic Researches on Construction of Space Cable” ST8, ID: 147 886, no:2011/01/B/ST8/03848, contract no: UMO-2011/01/B/ST8/03848.

\section{REFERENCES}

[1] Behery, H.M. (2005) Effects of mechanical and physical properties on fabric hand. Woodhead Publishing Limited, Cambridge.

[2] Ciesielska-Wrobel, I. and Van Langenhove, L. (2012) The hand of textiles-Definitions, achievements, perspectives-A review. Textile Research Journal, 82, 14571468. http://dx.doi.org/10.1177/0040517512438126

[3] McGlone, F. and Reilly, D. (2010) The cutaneous sensory system. Neuroscience \& Biobehavioral Reviews, 34, 148159. http://dx.doi.org/10.1016/j.neubiorev.2009.08.004

[4] Kandel, E.R., Schwartz, J.H. and Jessell, T.M. (2000) Principles of neural science. 4th Edition, McGraw-Hill, New York, 515-520.

[5] Ganong, W. (2009) Physiology (Polish: Fizjologia). Wydawnictwo Lekarskie PZWL, Warszawa.

[6] Johansson, R.S. and Flanagan, J.R. (2009) Coding and use of tactile signals from the fingertips in object manipulation tasks. Nature Reviews, 10, 345-359. http://dx.doi.org/10.1038/nrn2621

[7] Johnson, K.O. (2001) The roles and functions of cutaneous mechano-receptors. Current Opinion in Neurobiology, 11, 455-461.

[8] Flynn, C. and McCormack, B.A.O. (2010) Simulating the wrinkling and aging of skin with a multi-layer finite element model. Journal of Biomechanics, 43, 442-448. http://dx.doi.org/10.1016/j.jbiomech.2009.10.007

[9] Koutroupi, K.S. and Barbenel, J.C. (1990) Mechanical and failure behaviour of the stratum corneum. Journal of 
Biomechanic, 23, 281-287.

http://dx.doi.org/10.1016/0021-9290(90)90018-X

[10] Flynn, C. and McCormack, B. (2008) Finite element modeling of forearm skin wrinkling. Skin Research and Technology, 14, 261-269. http://dx.doi.org/10.1111/j.1600-0846.2008.00289.x

[11] Fung, Y.C. (1993) Biomechanics: Mechanical properties of living tissues. Springer-Verlag, New York.

[12] Lesniak, D.R. and Gerling, G.J. (2009) Predicting SA-I mechanoreceptor spike times with a skin-neuron model. Mathematical Biosciences, 220, 15-23. http://dx.doi.org/10.1016/j.mbs.2009.03.007

[13] Kendalla, M.A.F., Chongc, Y.-F. and Cock, A. (2007) The mechanical properties of the skin epidermis in relation to targeted gene and drug delivery. Biomaterials, 28, 4968-4977.

http://dx.doi.org/10.1016/j.biomaterials.2007.08.006

[14] Ciesielska, I.L. (2010) The precursory analysis of the influence of garments on corona discharge created around a human fingertip. Textile Research Journal, 80, 216-225. http://dx.doi.org/10.1177/0040517509105599 